\title{
Observation of Surface Microstructure of Tricalcium Silicate by Transmission Electron Microscopy
}

\author{
Masaaki HISA, Nelson SEMBIRING, Tatsuya SHIRAKAMI and Kazuyori URABE \\ Faculty of Science and Technology, Materials Chemistry, Ryukoku University, 1-5, Yokotani, Seta Oe-cho, Otsu-shi 520-2194
}

\author{
透過型電子顕微鏡によるケイ酸三カルシウム表面の微構造観察 \\ 久 正明 · Nelson Sembiring · 白神達也 · 浦部和順 \\ 龍谷大学理工学部物質化学科, 520-2194 大津市瀬田大江町横谷 1-5
}

\begin{abstract}
The surface microstructure of tricalcium silicate $\left(\mathrm{C}_{3} \mathrm{~S}\right)$ was observed by transmission electron microscopy (TEM). The tricalcium silicate specimen was dispersed in ethanol or isopropanol. It was then placed on a copper mesh with a collodion film that had an amorphous layer on the surface of each grain. The amorphous layer was caused by the hydration reaction of $\mathrm{C}_{3} \mathrm{~S}$ with water in the dispersants. The irradiation by an electron beam caused the layer to change into $\mathrm{CaO}$ crystallites with a concurrent formation of silica-rich domains.

[Received December 22, 1999; Accepted October 11, 2000]
\end{abstract}

Key-words : $C_{3} S$, TEM, Surface, CaO, Ethanol, Isopropanol

\section{Introduction}

The degradation of the hydration properties of Portland cement is caused by a reaction between cement clinker minerals and carbon dioxide in humid air.1),2) The reaction proceeds through the formation of calcium hydroxide in the surface layers of the clinker minerals and is followed by the carbonation of the reaction product. The phases of calcium carbonate are influenced by the temperature, humidity and carbon dioxide content of air. ${ }^{3)}$ The details of the phenomenon should be studied by microscopy because it is considered that the initial hydration on the surface of the clinker minerals plays an important role in the degradation of cement.

Microstructure analysis of clinker minerals has already been carried out in order to elucidate their hydration mechanism. Double hydration layers, termed inner and outer layers, were found in the surface layer of $\mathrm{C}_{3} \mathrm{~S}(3 \mathrm{CaO}$. $\left.\mathrm{SiO}_{2}\right)$ in a mortar. ${ }^{4), 5)}$ Portlandite $\left(\mathrm{Ca}(\mathrm{OH})_{2}\right)$ and calcite crystallites were identified in the outer layers. The microstructure of $\mathrm{C}_{3} \mathrm{~S}$ surfaces in Portland cement has also been observed by high-resolution transmission electron microscopy (HRTEM).6) Hydration layers on the surfaces of $\mathrm{C}_{3} \mathrm{~S}$ crystals were surrounded by 30 -nm-thick amorphous materials with small crystallites of less than $10 \mathrm{~nm}$ in diameter. These crystallites were presumed to be composed of calcium carbonates. However, the fringes in lattice images of the crystallites did not accurately match any plane spacing of calcite.

In this study, we prepared $\mathrm{C}_{3} \mathrm{~S}$ specimens under three different conditions, and analyzed both crystalline and amorphous parts of the surface layers on the specimens using an energy-dispersion X-ray analyzer which was equipped with a Transmisson electron microscope (TEM) as a new approach. The results facilitated the identification of the crystallites in the surface layers of $\mathrm{C}_{3} \mathrm{~S}$, from which the newly obtained lattice images of the crystallites were obserbed using TEM.

\section{Experimental}

$\mathrm{A} \mathrm{C}_{3} \mathrm{~S}$ specimen was synthesized from calcite $\left(\mathrm{CaCO}_{3}\right)$ and silicon dioxide (99.9\%). A mixture of the starting materials with a stoichiometric ratio was fired in an electric furnace at $1400^{\circ} \mathrm{C}$ for $6 \mathrm{~h}$. The fired specimen was identified by X-ray diffraction (XRD) analysis.

In order to describe the influence of water content in dispersants on the microstructure of the $\mathrm{C}_{3} \mathrm{~S}$ crystal surfaces, the $\mathrm{C}_{3} \mathrm{~S}$ specimen was pulverized and dispersed in ethanol with 5 mass $\%$ water or in isopropanol with about 0.5 mass $\%$ water. The water content in ethanol must be reproducible because $95 \%$ ethanol is an azeotrope mixture. The reproducibility of the water content in isopropanol may be lower than that in ethanol, however, the water content in isopropanol is lower than that in ethanol by at least about one order of magnitude.

The dispersed specimens were placed on copper meshes with microgrids and were dried in an oven at $100^{\circ} \mathrm{C}$ for one hour under vacuum. The specimen was handled under a nitrogen atmosphere and prepared by crushing it, scooping it onto the microgrid and mounting it on a double-tilt-type goniometer. In all of these procedures, there was almost no chance for the specimen to react with carbon dioxide. Three specimens were observed by TEM on a JEM-4000EX (JEOL) at $400 \mathrm{kV}$ and on a JEM-3000F (JEOL) equipped with an energy-dispersive spectroscope (EDS) at $300 \mathrm{kV}$. The characteristic X-ray intensities of $\mathrm{Si}$ and $\mathrm{Ca}$ atoms were measured and ratios of $\mathrm{CaO} / \mathrm{SiO}_{2}(\mathrm{C} / \mathrm{S})$ were obtained by the correction method with no internal standard using the program "Voyager."

\section{Results and discussion}

The fired specimen was confirmed by XRD to be composed of a triclinic phase of $\mathrm{C}_{3} \mathrm{~S}$, TI; a small amount of calcium oxide was found. The TI phase is thought to be a modulated structure of the rhombohedral basic cell. The cell parameters are $a=0.708 \mathrm{~nm}$ and $c=2.52 \mathrm{~nm}$ when a hexagonal lattice expression is employed. ${ }^{7}$

Figure 1 shows a TEM image of a grain of the specimen dispersed in ethanol that was recorded with a magnification of $1.5 \times 10^{5}$. The edge of the grain had a different microstructure from that of the inner region, forming a layer on the surface. A selected area diffraction (SAD) pattern of the layer is shown in Fig. 2. The layer was identified to be amorphous because of a lack of lattice in the image shown in Fig. 1 and the presence of a halo in the SAD pattern shown in Fig. 2.

Figure 3 shows the details of the amorphous layer record- 


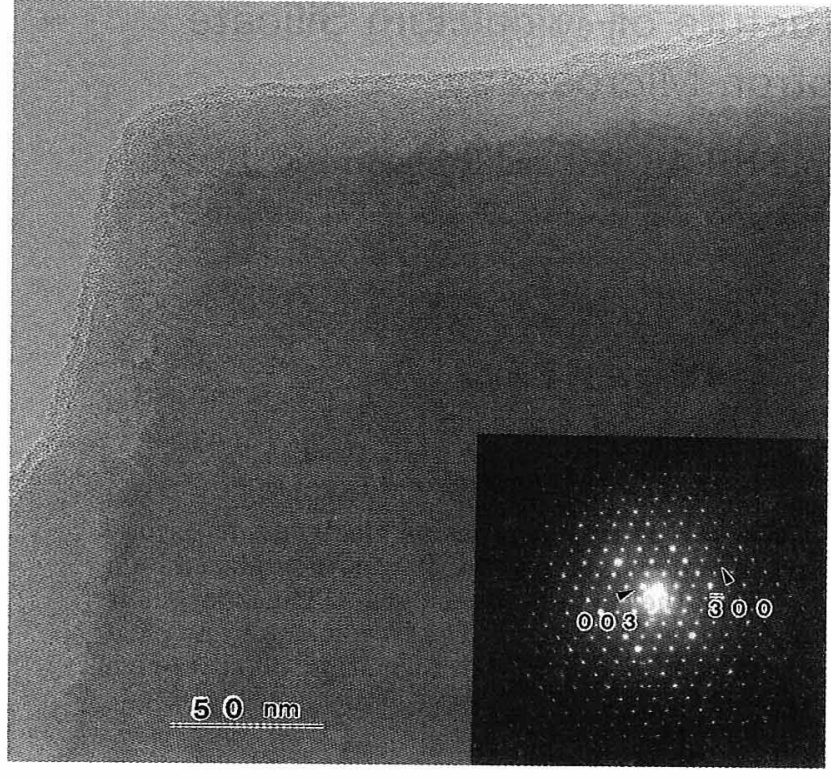

Fig. 1. TEM image of ethanol-dispersed $\mathrm{C}_{3} \mathrm{~S}$ grain magnified 1.5 $\times 10^{5}$ times which shows an amorphous layer on a grain surface. Inset is the diffraction pattern of grain. Indices are based on a fundamental cell, and reflections between fundamental reflections are for superstructure characteristic of the TI phase.

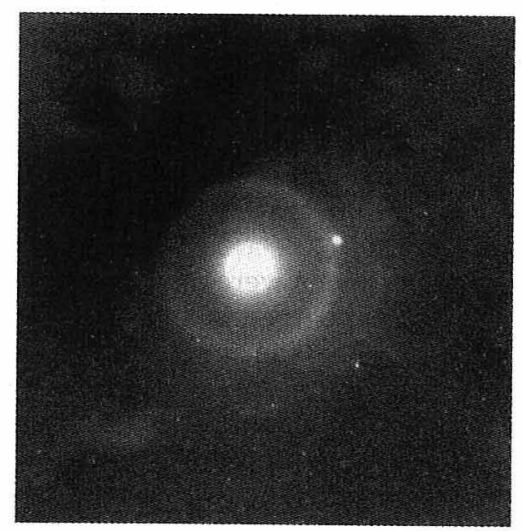

Fig. 2. SAD pattern of amorphous layer of the grain shown in Fig. 1.

ed with a magnification of $6 \times 105$. Crystallites of $3-8$ nanometers in diameter were observed in the amorphous layer. These were not detected in the image shown in Fig. 1. These crystallites, therefore, are thought to be formed by the thermal effect of the electron beam radiation. In the recording of high-magnification images, the electron beam is condensed into a narrow region in order to maintain the proper brightness for observation, which increases the temperature in the region.

A SAD pattern from a region in the amorphous layer including the mentioned crystallites is shown in Fig. 4. Three Debye-Sherrer rings were observed whose interplanner distances were $0.28,0.24$ and $0.17 \mathrm{~nm}$; these distances from the crystalline $\mathrm{CaO}$ reflections with high intensities were located on the rings, indicating that larger crystallites acted as single crystals in the reflection. Repeat distances of the lattice fringes observed in Fig. 3 agreed with those of the $\mathrm{CaO}$ lattice.

The C/S ratios evaluated from EDS data are shown in

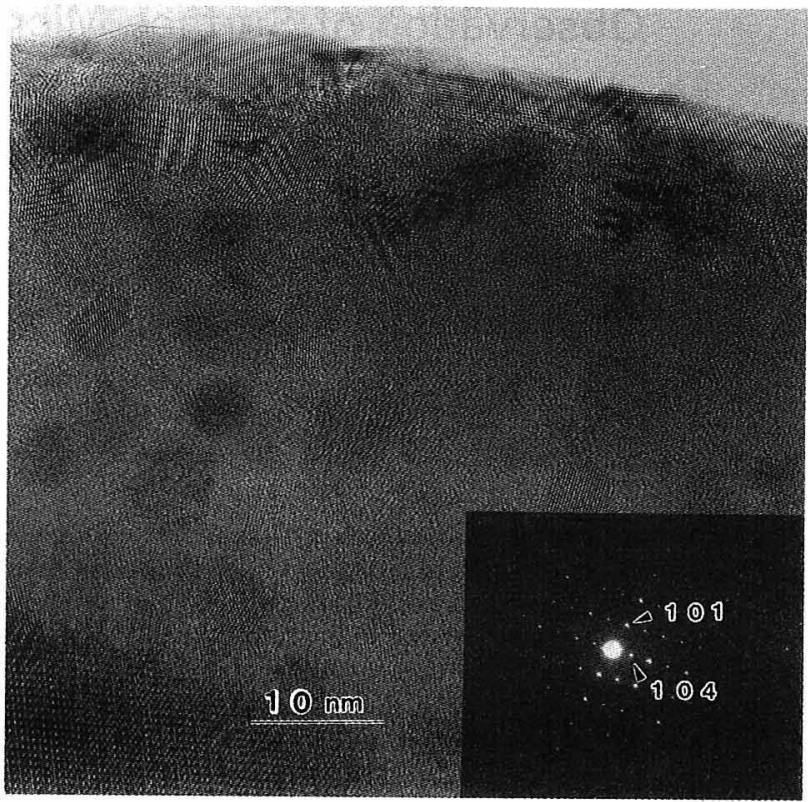

Fig. 3. Detail of an amorphous layer of ethanol-dispersed grain. Fringes in the surface layer are for $\mathrm{CaO}$ crystallites. Inset is a SAD pattern of $\mathrm{C}_{3} \mathrm{~S}$, whose lattice image is in the bottom-left corner.

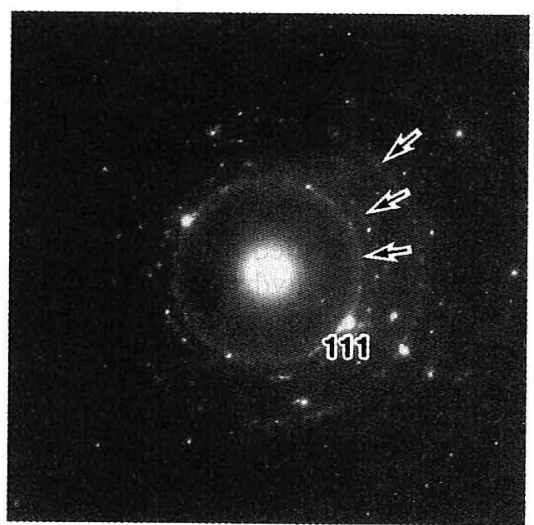

Fig. 4. SAD pattern of the layer shown in Fig. 3. Three Debye-Sherrer rings and diffraction spots on rings are for calcium oxide. Indices are for calcium oxide with a cell parameter of 0.556 nm.

Fig. 5. These values were distributed, even in the $\mathrm{C}_{3} \mathrm{~S}$ specimen, from 2.4 to 3.4 due to the influence of thickness of the amorphous layer where the electron beam passed through. The amorphous layer had $\mathrm{C} / \mathrm{S}$ values that were distributed over a range wider than that of $\mathrm{C}_{3} \mathrm{~S}$ grains. The highest value was 6.24 , which was obtained in a particle. The particle was identified to be a $\mathrm{CaO}$ crystallite because of the parallel arrangement of characteristic lattice fringes on the TEM screen. The wider distribution implied that the homogeneous amorphous material in Fig. 1 was converted into $\mathrm{CaO}$ crystallites and $\mathrm{CaO}$-deficient amorphous materials. There is no direct evidence that the amorphous material is $\mathrm{CaO}$-deficient, however, this composition was conceivable from the finding that $\mathrm{C}_{3} \mathrm{~S}$ decomposed into $\mathrm{CaO}$ and $\mathrm{C}_{2} \mathrm{~S}$ below $1250^{\circ} \mathrm{C} .{ }^{8)}$

An amorphous layer found in a grain dispersed in isopropanol is shown in Fig. 6. The layer also contained $\mathrm{CaO}$ crystallites although the sizes of the crystallites were 
different from those shown in Fig. 3. All of the grains had amorphous layers although the thickness varied between grains. The difference in water content between the dispersants did not always reflect the thickness of the layers. Such differences, therefore, may be caused by the difference in grain surface properties and/or soaking times in the dispersants, which were not strictly controlled in this experiment.

Figure 7 shows an image of a grain of the specimen that was handled and mounted on the TEM holder under a nitrogen atmosphere. The structural orientation of $\mathrm{C}_{3} \mathrm{~S}$ was traced from the inside to the edge of the grain and was distorted in the region immediately beneath the edge.

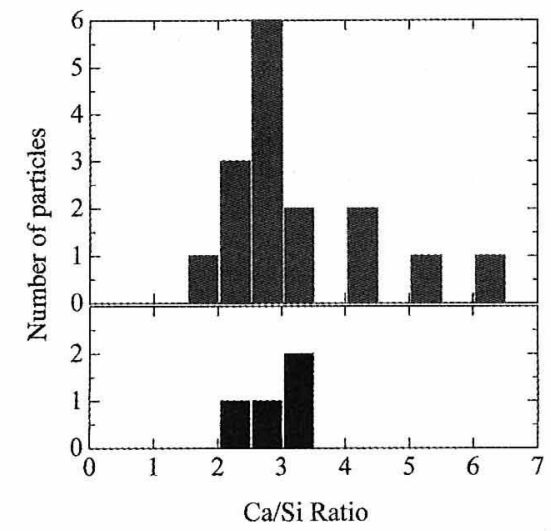

Fig. 5. Variation in $\mathrm{CaO} / \mathrm{SiO}_{2}$ ratio in amorphous layer containing crystallites of calcium oxide (top) and $\mathrm{C}_{3} \mathrm{~S}$ crystal (bottom).
However, the amorphous layer did not exist. Fringes with $0.29-\mathrm{nm}$ repeat marked in the figure corresponded to the (200) spacing of the $\mathrm{C}_{3} \mathrm{~S}$ basic cell and were parallel to those observed in the inner part. This finding suggests that regions with $0.29-\mathrm{nm}$ fringes were the $\mathrm{C}_{3} \mathrm{~S}$ crystal. The $0.30-\mathrm{nm}$ fringes that had a spacing slightly larger than that of $\mathrm{C}_{3} \mathrm{~S}$, were not parallel to those found in the inner part. The region of the $0.30-\mathrm{nm}$ fringes may be a crystallite of $\mathrm{CaO}$ formed directly from $\mathrm{C}_{3} \mathrm{~S}$ by the electron-beam irradiation.

From the results, it was deduced that the amorphous layers were formed by the reaction between $\mathrm{C}_{3} \mathrm{~S}$ and the water in the dispersants. The water in the dispersants, approximately 5 and 0.5 mass\% in ethanol and isopropanol, respectively, was probably responsible for the reaction. The amorphous material of the layer had a homogenous composition, as was described by Groves et al. ${ }^{5)}$ This layer was easily converted into $\mathrm{CaO}$ crystallites by irradiation of an electron beam.

\section{Conclusions}

The surfaces of $\mathrm{C}_{3} \mathrm{~S}$ grains were observed by HRTEM and the following results were obtained. The grains dispersed in ethanol or isopropanol were surrounded by amorphous layers, while the grains prepared under a nitrogen atmosphere had amorphous-free surfaces. The water in the dispersants was responsible for the formation of the amorphous layers. $\mathrm{CaO}$ crystallites were formed in the amorphous layers by the irradiation of the electron beam. A wider distribution in the chemical composition of the amorphous layers was obtained which suggests that the amorphous material was converted into $\mathrm{CaO}$ crystallites, and that the amorphous material is $\mathrm{CaO}$-deficient.

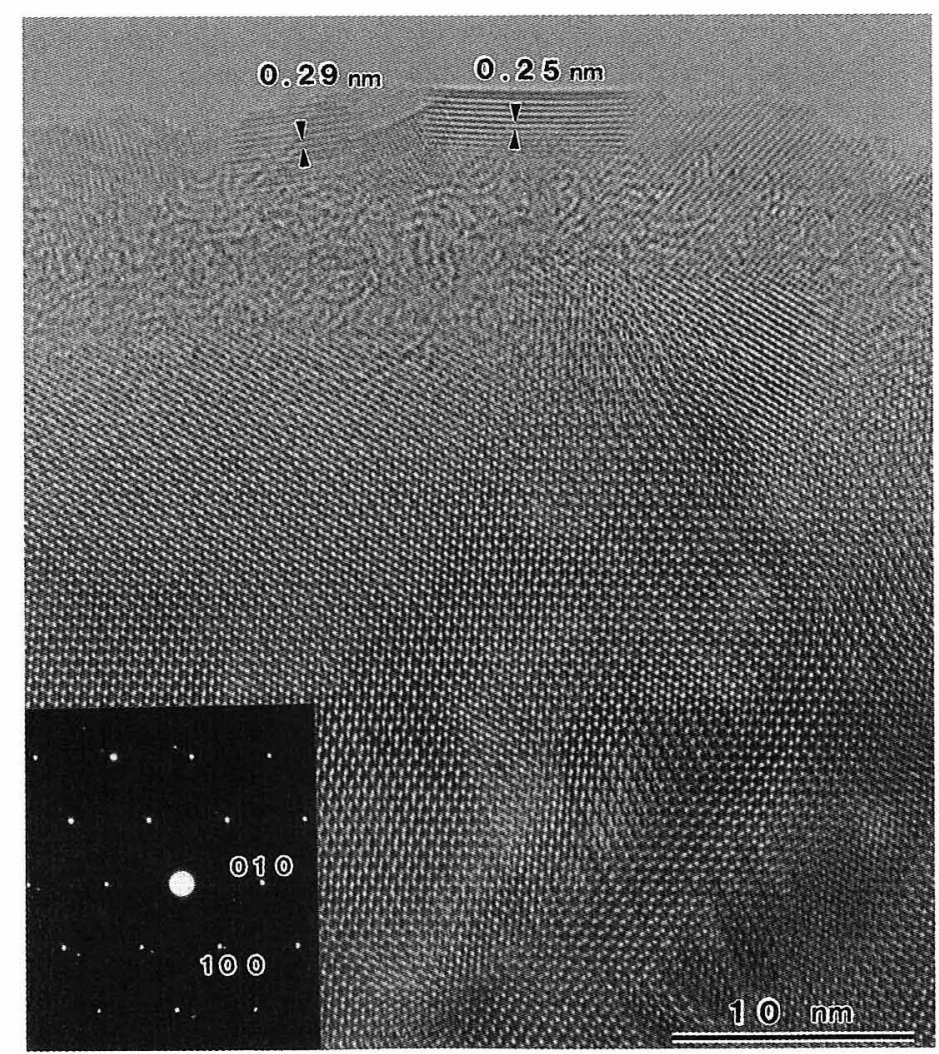

Fig. 6. TEM image of surface of isopropanol-dispersed $\mathrm{C}_{3} \mathrm{~S}$ grain. Fringes repeating with sequences of 0.29 and $0.25 \mathrm{~nm}$ are for $\mathrm{CaO} \mathrm{crys}-$ tallites. Inset is a SAD pattern of $\mathrm{C}_{3} \mathrm{~S}$. 


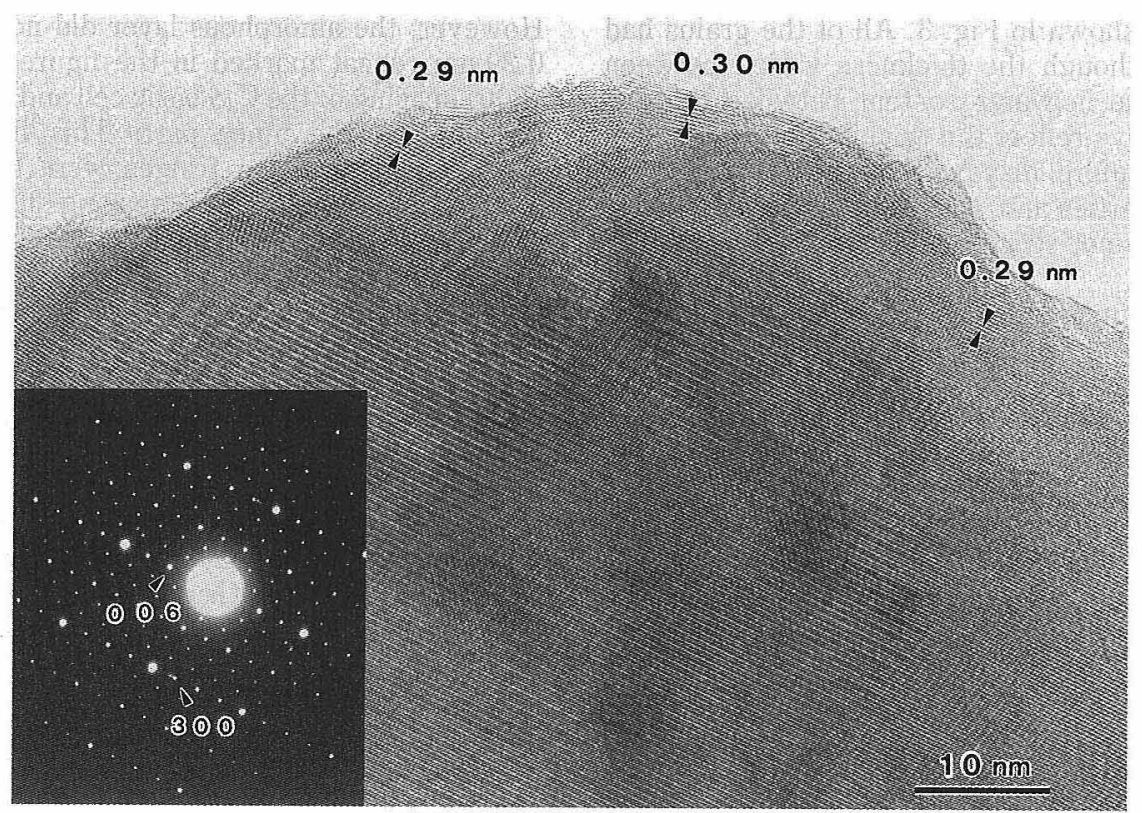

Fig. 7. TEM image of surface of grain mounted on a specimen under nitrogen atmosphere.

Acknowledgement The authors wish to express thanks to Mr. Hiroyasu Morita of Ryukoku University for help with the TEM observation.

\section{References}

1) K. Watanabe, Semento Gijyutunenpo, 4, 70-74 (1950) [in Japanese].

2) K. Watanabe, Semento Gijyutunenpo, 6, 18-26 (1952) [in Japanese].

3) K. Takemoto and Y. Saiki, J. Soc. Inorg. Mater. Japan (Gypsum
\& Lime), 81, 4-12 (1966) [in Japanese].

4) H. M. Jennings, B. J. Dalgleish and P. L. Pratt, J. Am. Ceram. Soc., 64, 567-72 (1981)

5) G. W. Groves, P. L. Le Sueur and W. Sinclair, J. Am. Ceram. Soc., 69, 353-56 (1986)

6) K. Urabe and T. Morita, JCA Proc. of Cem. Concr., 48, 46-51 (1994) [in Japanese].

7) I. Maki and K. Kato, Cem. and Concr. Res., 12, 93-100 (1982).

8) J. H. Welck and W. Gutt, J. Am. Ceram. Soc., 42, 11-15 (1959). 